- Thirty-eight percent of treated children reported post-operative pain and 25\% used analgesic agent post-operatively.

- Contrary to high pressure intraligamental anaesthesia, intra-sulcular injection administered by a computerised delivery system did not increase the incidence or duration of post-operative pain.

- The highest incidence of post-operative pain was found after root canal treatment, preformed crowns and extractions.

- Performance of multiple restorations did not increase the incidence or duration of post-operative pain.

- Prediction and treatment of post-operative pain should be an integral part of professional paediatric care.

\title{
Post-operative pain and use of analgesic agents in children following intrasulcular anaesthesia and various operative procedures
}

\author{
M. Ashkenazi, ${ }^{1}$ S. Blumer ${ }^{2}$ and I. Eli ${ }^{3}$
}

\author{
Aim To characterise post-operative pain (PDP) and use of analgesic \\ agents in children.
}

Methods The study consisted of 472 children, who received routine dental treatment. Teeth were anaesthetised by a computerised delivery system, either intrasulculary (CDS-IS) or by local infiltration (CDS-IF). Information regarding post-operative pain and use of analgesic agents was obtained by a telephone call within 24 hours after treatment.

Results The overall incidence of PDP was 38\%. $60.9 \%$ of the children who experienced PDP were given an analgesic agent. Incidence and severity of pain were significantly associated with type of dental procedure. The highest incidence was found after root canal treatment (62.5\%) and preformed crowns (60.8\%). A higher incidence of PDP was found in teeth with history of pain or abscess as compared to teeth with restoration or caries $(p<0.01)$. Incidence of pain was not associated with restoration material, extension, depth or type (occlusal vs proximal) of restoration, multiple restoration, gender, mode of CDS anaesthesia, or effectiveness of anaesthesia during dental treatment. Analgesic drugs were given mainly after preformed crowns, root canal filling and extractions.

Conclusions PDP and analgesic use in children is common, especially after root canal filling, preformed crowns and extractions. CDS-IS is not associated with increased PDP.

\section{INTRODUCTION}

Although children who suffer from pain are usually able to describe and quantify their experience, ${ }^{1,2}$ post-operative dental pain (PDP) has largely remained unexamined. After tooth

\footnotetext{
${ }^{1 *}$ Lecturer, ${ }^{2}$ Instructor, Department of Pediatric Dentistry, The Maurice and Gabriela Goldschleger School of Dental Medicine, Tel-Aviv University, Tel-Aviv, Israel; ${ }^{3}$ Professor, Department of Oral Rehabilitation, The Maurice and Gabriela Goldschleger School of Dental Medicine, Tel-Aviv University, Tel-Aviv, Israel

${ }^{*}$ Correspondence to: Dr Malka Ashkenazi

Email:shkenazi@post.tau.ac.il
}

extraction, $38 \%$ of the children reported $\mathrm{PDP}^{3,4}$ compared to $32 \%$ of children undergoing routine restorative treatment. ${ }^{5}$

Long post-operative pain has been associated with intraligamental anaesthesia injected by a high-pressure syringe. ${ }^{6,7}$ Recently, a new technique for anaesthetising primary teeth was introduced.$^{8,9}$ In this technique, the local anaesthetic solution is delivered to a similar area as the high pressure intraligamental injection (intrasulculary), but the solution is delivered by a low pressure computerised delivery system (CDS) (Wand, Milestone Scientific, Inc. Deerfield, IL, USA) rather than by a pressure syringe. Recently, a 31.4\% incidence of PDP was reported after a low pressure intrasulcular injection with the use of the CDS. ${ }^{8}$ However, there are no studies comparing PDP after employing the CDS for different modes of injection (eg intrasulcular anaesthesia versus infiltration).

A common reaction to pain complaints is to provide a painrelieving drug. However, both clinicians and parents often do not give serious consideration to PDP relief for children. ${ }^{1,2,5}$ The reported use of analgesic agents after dental treatment is limited to $17-22 \%$ of children undergoing restorative dental procedures or extractions and refers only to 53-59\% of the children who report pain..$^{3-5}$ Notwithstanding, over time the use of analgesic agents for post-operative pain management in children is increasing. ${ }^{10}$ Ashkenazi et $a l .{ }^{8}$ reported that $64.9 \%$ of children who reported PDP received pain relieving medication as a result.

The purpose of this study was to evaluate the incidence of PDP and the use of analgesic agents in children with regard to age, gender, type of behaviour modification, tooth history, mode of injection (intrasulcular $v s$ infiltration), effectiveness of anaesthesia, type of restoration, type of material used, depth of restoration, extent of restoration, and number of teeth restored during a single appointment.

\section{SUBJECTS AND METHODS}

The study population consisted of 472 children, aged two to 15 years (mean $6.8 \pm 3.2$ years, 52\% girls), who attended 
routine dental treatment in one of two specialised paediatric dental clinics. Both clinics accept patients from all socioeconomic levels.

A structured form was designed to include information regarding the patient's age, gender, tooth location, tooth history (caries lesion, previous restoration, pre-operative pain and dento-alveolar abscess), kind of local anaesthesia administered, dental treatment (restoration, stainless steel crown alone or combined with pulpotomy, root canal treatment and extraction), effectiveness of anaesthesia and behaviour management approaches.

\begin{tabular}{|c|c|c|c|c|}
\hline \multirow{2}{*}{$\begin{array}{l}\text { Treatment } \\
\text { mode }\end{array}$} & \multicolumn{3}{|c|}{ Age groups } & \multirow{2}{*}{ Total } \\
\hline & $2-4 \mathrm{yrs}$ & $5-9$ yrs & $>9$ yrs & \\
\hline BM & 8 & 83 & 65 & 156 \\
\hline $\mathrm{N}_{2} \mathrm{O}$ & 13 & 89 & 16 & 118 \\
\hline SED & 104 & 67 & 1 & 172 \\
\hline Total & 125 & 239 & 82 & $\begin{array}{l}446 \text { (miss- } \\
\text { ing data 26) }\end{array}$ \\
\hline
\end{tabular}

\begin{tabular}{|c|c|c|c|}
\hline $\begin{array}{l}\text { Operative } \\
\text { procedure }\end{array}$ & $\begin{array}{l}\text { Total number } \\
\text { of children in } \\
\text { the group* } \\
(\%)\end{array}$ & $\begin{array}{l}\text { Number of } \\
\text { children report- } \\
\text { ing pain }(\%)\end{array}$ & $\begin{array}{l}\text { Number of } \\
\text { children taking } \\
\text { medication } \\
(\%)\end{array}$ \\
\hline Restorations & $231(100)$ & $72 / 231(31.2)$ & $28 / 225^{* *}(12.4)$ \\
\hline Composite crown & $7(100)$ & $1 / 7(12.5)$ & $1 / 7(12.5)$ \\
\hline Extractions & $84(100)$ & $36 / 84(42.8)$ & $16 / 75^{* *}(21.3)$ \\
\hline $\begin{array}{l}\text { Preformed } \\
\text { crowns without } \\
\text { pulpotomies }\end{array}$ & $30(100)$ & $20 / 30(66.7)$ & $17 / 27^{* *}(63.0)$ \\
\hline $\begin{array}{l}\text { Preformed crowns } \\
\text { with pulpotomies }\end{array}$ & $39(100)$ & $22 / 39(56.4)$ & $10 / 35^{* *}(28.6)$ \\
\hline Root canal fillings & $8(100)$ & $5 / 8(62.5)$ & $3 / 7^{* *}(42.9)$ \\
\hline Sealants & $33(100)$ & $1 / 33(3)$ & 1/33 (3) \\
\hline Total & $472(100)$ & 179/472 (37.9) & $86 / 445^{* *}(19.2)$ \\
\hline \multicolumn{4}{|c|}{ * Numbers representing number of cases in each category } \\
\hline
\end{tabular}

\begin{tabular}{|c|c|c|}
\hline Restorations & $\begin{array}{l}\text { Number of children } \\
\text { reporting pain* }(\%)\end{array}$ & $\begin{array}{l}\text { Number of children } \\
\text { taking medication } \\
(\%)\end{array}$ \\
\hline Composite & 44/161 (27.3) & $21 / 160^{* *}(13.1)$ \\
\hline Amalgam & 30/82 (36.6) & $15 / 81^{* *}(18.5)$ \\
\hline Occlusal & 20/81 (24.7) & $7 / 80^{* *}(8.8)$ \\
\hline Proximal & $51 / 148(34.5)$ & 27/148 (18.2) \\
\hline 1-2 mm depth & $17 / 68(25)$ & $6 / 67^{* *}(9)$ \\
\hline$>2 \mathrm{~mm}$ depth & $21 / 49$ (42.9) & $9 / 48^{* *}(18.8)$ \\
\hline$\leq 1 / 4$ of occlusal table & 16/63 (25.4) & $5 / 63(7.9)$ \\
\hline$>1 / 4$ of occlusal table & 21/53 (39.6) & $9 / 51^{* *}(17.6)$ \\
\hline
\end{tabular}

Children were allocated to three different behavioural management approaches as follows: Group A - behaviour modification techniques only (BM); Group B - inhalation of $\mathrm{N}_{2} \mathrm{O}$ /oxygen (up to $\left.45 \% \mathrm{~N}_{2} \mathrm{O}\right)\left(\mathrm{N}_{2} \mathrm{O}\right)$; and Group $\mathrm{C}$ - sedation by intra-rectal midazolam $(0.4 \mathrm{mg} / \mathrm{kg}$, up to a maximal dose of 7.5 mg) (SED).${ }^{11}$ Allocation of children to the different groups was according to their ability to cooperate with treatment.

Restorations were classified according to the material (composite or amalgam restoration), type (proximal or occlusal restoration), depth (1-2 mm, >2 mm), and extension (up to $1 / 4$ of occlusal table, $>1 / 4$ of occlusal table). Depth of restorations was estimated with the use of a periodontal probe.

A low-pressure computerised delivery system (CDS) (Wand, Milestone Scientific, Inc, Deerfield, IL, USA) was used to anaesthetise the teeth. Primary teeth were anaesthetised as follows: (i) in the mandible - intrasulcular anaesthesia; (ii) in the maxilla - either local infiltration or intrasulcular anaesthesia. Permanent teeth were anaesthetised as follows: (i) in the mandible - mandibular block or intrasulcular anaesthesia; (ii) in the maxilla - infiltration only.

The modes of anaesthesia were described in detail previously. ${ }^{8}$ Immediately after delivery, a rubber dam was applied for all operative procedures. Amalgam or composite restorations were carried out by applying total etching for $20 \mathrm{~s}$, followed by rinsing for $20 \mathrm{~s}$ and single bond (3M Dental Products, St. Paul, MN, USA). Teeth that were treated with only sealant and/or small preventive resin restoration were not anaesthetised.

\section{Effectiveness of anaesthesia}

During treatment, the dentist assessed the effectiveness of anaesthesia through the presence or absence of pain disruptive behaviour. Each single, even mild, sign of discomfort was rated as a positive presence of pain. ${ }^{8}$

Evaluation of PDP and use of analgesic drugs $24 \mathrm{~h}$ post-operatively Dentists avoided suggestions regarding PDP or analgesics during and immediately after treatment. Any posed questions (by child or parent) were answered but no prescriptions for pain medications were given. A secretary, unaware of the treatment performed, telephoned parents eight to $24 \mathrm{~h}$ post-operatively, to request a report regarding PDP and/or use of analgesic drugs by children. Parents were asked to involve the child in their answers if they were mature enough. The child was excluded from the study if parents could not be reached within $24 \mathrm{~h}$. All reachable parents responded to the questionnaire.

\section{Statistical analysis}

Pearson Chi-Square test was used to evaluate the associations between post-operative pain or analgesic usage and the above variables. $\mathrm{P}<0.05$ was considered as significant difference.

\section{RESULTS}

All patients who could be reached by telephone $(93 \% ; 472$ out of 507 patients) agreed to respond to the questionnaire $(100 \%$ response rate).

\section{Treatment groups}

The distribution of the children according to age and behavioural management approaches is shown in Table 1. 


\section{Treated teeth}

Since several patients had more than one tooth per quadrant treated during the same session, only the most invasive procedure per session was analysed. Accordingly, 472 procedures were evaluated for PDP in 64 primary maxillary first molars, 108 primary maxillary second molars, 79 primary mandibular first molars, 107 primary mandibular second molars, 48 primary maxillary incisors, 10 permanent premolars, 49 permanent first molars and 7 permanent maxillary incisors.

\section{Post-operative pain}

The mean incidence of PDP was 38\% (179/472).

\section{Effect of treatment procedures on PDP and analgesic use}

(Tables 2 and 3)

Root canal treatment and preformed stainless steel crowns, with or without pulpotomy, induced a significantly higher incidence of PDP compared to extraction, restorations, and sealant ( $p<0.0001)$. Performance of crown with or without pulpotomy showed similar incidence of post operative pain ( $p$ $=0.69)$ and analgesic use $(p=0.43)$. Incidence of PDP was not associated with types of restorations (occlusal vs proximal), restorative material (amalgam vs composite resin), depth of restoration, extension of restoration or number of teeth treated in the quadrant. Performance of single or multiple restorations had no significant effect on the incidence of post operative pain $(p=0.09)$ or on analgesic use $(p=0.80)$.

\section{Effect of age, gender and treatment mode on PDP and analgesic} use (Table 4)

There were no differences in the PDP incidence between genders. PDP was comparable in all age groups, but significantly less PDP was reported by children treated using the BM approach compared to the $\mathrm{N}_{2} \mathrm{O}$ or SED ( $\left.\mathrm{p}<0.0001\right)$ approaches. A significantly lower level of pain was reported in the $\mathrm{N}_{2} \mathrm{O}$ group compared to the SED group ( $p<0.005)$.

\section{Effect of injection on PDP and analgesic use (Table 5)}

Incidence of PDP and analgesic use were unaffected by type of injection (local infiltration or intrasulcular injection). Children who did not receive local anaesthesia at all (sealant or small preventive resin restoration without rubber dam) reported significantly less PDP $(10.3 \%$; $p<0.0001)$ than children who did receive local anaesthesia (40.5\% for CDS-IS and $42.9 \%$ for CDS-IF).

\section{Effect of tooth history on PDP}

Tooth history was significantly associated with PDP and analgesic use. Children who received treatment in carious teeth or with defective restorations reported significantly less PDP and less analgesic use compared to children with pre-operative pain or dento-alveolar abscess; 43\% (78/182) and 25\% $(45 / 180)$ as compared with 65\% (17/26) and 46\% (12/26), respectively, $\mathrm{p}<0.05$.

\section{Duration of pain (Fig. 1)}

PDP was reported up to $2 \mathrm{~h}$ after treatment by most (70\%) patients. Duration of pain was not associated with dental procedure.

\section{Analgesic use (Tables 2-5)}

Analgesic drugs were given to $25 \%$ of the patients (65.9\% who reported PDP). Preformed crowns (with or without pulpotomy), root canal treatment and extractions were more frequently associated with the use of analgesic drugs compared to restorations, composite crowns or sealants ( $p<0.001)$. Similarly, history of pain or dento-alveolar abscess pre-treatment was more frequently associated with the use of analgesic drugs post-treatment compared to history of caries or previous defective restoration $(\mathrm{p}<0.05)$. Children treated by $\mathrm{N}_{2} \mathrm{O}$ or SED were given significantly more analgesic than children treated by BM only ( $\mathrm{p}<0.005)$. In contrast, no significant difference in analgesic use was found between age groups, gender, type of anaesthesia (infiltration $v s$ intrasulcular), effectiveness of anaesthesia, restoration material used, depth of restoration and

\begin{tabular}{|c|c|c|}
\hline Variables & $\begin{array}{l}\text { Number of children } \\
\text { reporting pain* }(\%)\end{array}$ & $\begin{array}{l}\text { Number of children } \\
\text { taking analgesic (\%) }\end{array}$ \\
\hline BM & $46 / 164$ (28) & $25 / 164$ (15.2) \\
\hline $\mathrm{N}_{2} \mathrm{O}$ & $54 / 123$ (43.9) & $38 / 123$ (30.9) \\
\hline SED & $73 / 176$ (41.5) & $50 / 174^{* *}(28.7)$ \\
\hline $2-4$ yrs & $53 / 128(41.4)$ & $33 / 127^{* *}(26)$ \\
\hline $5-9$ yrs & $97 / 244$ (39.8) & $64 / 244(26.2)$ \\
\hline$>9$ yrs & $32 / 84(38.1)$ & 16/84 (19) \\
\hline Boys & $79 / 204$ (38.7) & $50 / 204(24.5)$ \\
\hline Girls & $83 / 226$ (36.7) & $59 / 224^{* *}(26.3)$ \\
\hline \multicolumn{3}{|c|}{$\begin{array}{l}\text { *Numbers represent the number of patients reporting the symptom and the } \\
\text { total number of children in the specific treatment mode, age or gender group } \\
\text { **Differences in numbers of children in the group due to missing data }\end{array}$} \\
\hline
\end{tabular}

\begin{tabular}{|c|c|c|}
\hline Anaesthesia & $\begin{array}{l}\text { Number of children } \\
\text { reporting pain* }(\%)\end{array}$ & $\begin{array}{l}\text { Number of children } \\
\text { taking analgesic }(\%)\end{array}$ \\
\hline CDS-IS** & $100 / 247(40.5)$ & $61 / 246^{* * *}(24.8)$ \\
\hline CDS-IF** & $69 / 161(42.9)$ & $50 / 160^{* * *}(31.3)$ \\
\hline No injection & $4 / 39(10.3)$ & $1 / 39(2.6)$ \\
\hline \multicolumn{3}{|c|}{$\begin{array}{l}{ }^{*} \text { Numbers represent the number of patients reporting the symptom and the } \\
\text { total number of children in the specific injection mode } \\
{ }^{* *} \text { CDS-IS - intrasulcular injection; CDS-IF - infiltration } \\
{ }^{* *} \text { Differences in numbers of children in the group due to missing data }\end{array}$} \\
\hline
\end{tabular}

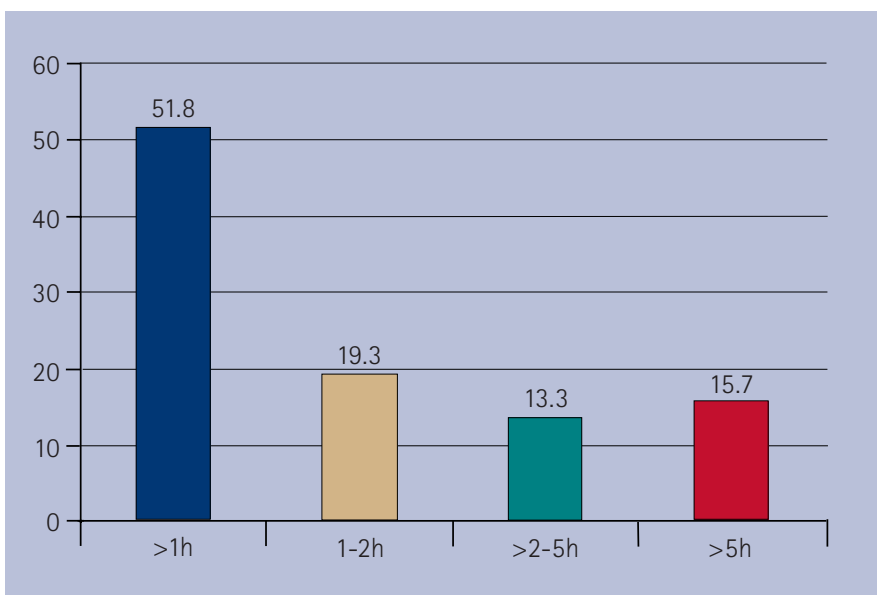

Fig. 1 Distribution of patients reporting different durations of post-operative pain 
size of restoration. The effect for type of restoration (occlusal vs proximal) was marginal $(\mathrm{p}=0.078)$.

Type of analgesic agent used

Of the 67 parents who responded to this question, 34 (50.7\%) used paracetamol, 31 (46.3\%) non-steroidal anti-inflammatory drugs, and only 2 (3\%) optalgin.

\section{DISCUSSION}

The incidence of pain after different dental procedures has gained little attention in the literature. The present study showed that the overall incidence of PDP in children was high $(38 \%)$, which confirms the results of Acs et al. and Acs and Drazner, ${ }^{3-5}$ and are markedly lower than the incidence of PDP in adult dental patients, ranging from $70.7 \%$ to $78 \% .^{12,13}$

PDP and use of analgesic agents (an indirect indicator of intensity of pain) were more frequent after preformed crowns, root canal treatment and extractions. The reasons for the high frequency of PDP following preformed crowns could be related to the pressure exerted from the crown margin into the gingival sulcus, and to possible pressure on the tooth by a plunger cusp, since it is difficult to completely adjust occlusion after placement of a preformed crown. Although type of treatment was correlated with PDP, it is still possible that some of the younger children may feel the pain but are not able to correctly localise it. The fact that there was no effect of multiple restorations (as compared to a single restoration) on the incidence of PDP indicates that this effect is probably marginal.

There was no relation between PDP and the restorative material used, type of restoration, depth of restoration, and extent of restorations. This may be due to routine use of an etching and bonding technique in both amalgam and composite restorations, which improves the marginal seal of both types of restorations. Moreover, the routine use of rubber dam in occlusal, as in proximal restoration, can override the PDP induced by placing the matrix band and wedge used in proximal restorations.

Adult female patients report PDP more frequently than males. ${ }^{14,15}$ In children, gender-related PDP has shown conflicting results. ${ }^{3,5}$ In the present study, gender was non-contributory to frequency of PDP.

Interestingly, although intra-sulcular injection administered by low-pressure (CDS) is delivered to the same area as the high pressure intraligamental injection, it did not increase the incidence or duration of PDP as compared to infiltration. This is contrary to intraligamental anaesthesia injected by a high pressure syringe, which does lead to a higher incidence of PDP. ${ }^{6}$ This can be explained by the fact that the CDS allows the operator to inject the anaesthetic solution under low pressure
(165 psi), which enables laminar diffusion into the attached gingiva and adjacent bone, and avoids damage to the adjacent tissue. In contrast, the intraligamental anaesthesia, injected by a high pressure syringe, induces high pressure on the tissue $(1,200$ psi) that can cause ischemia, transitional necrosis of the adjacent bone and long post-operative pain. ${ }^{6}$

Behaviour management mode (BM, $\left.\mathrm{N}_{2} \mathrm{O}, \mathrm{SED}\right)$ was significantly associated with prevalence of PDP, which indicates that anxious children who need $\mathrm{N}_{2} \mathrm{O}$ or sedation for their dental treatment may be more prone to experience PDP. ${ }^{16}$

In the present study, $65.7 \%$ of all children who reported PDP received an analgesic, which is higher than previously reported (52.9\%) and comparable to adults (68.3\%). ${ }^{3,12}$ Possibly this indicates an increased awareness for PDP relief in children. ${ }^{10}$ It is our belief that prediction and treatment of PDP should be an integral part of professional paediatric care.

\section{CONCLUSION}

The general incidence of PDP in children is approximately $38 \%$, being highest after root canal treatment, preformed crowns and extractions. Intrasulcular injection by a computerised delivery system did not cause more PDP than infiltration performed by the same system.

The authors thank Ms Ilana Gelerenter for her help in statistical analysis and Ms Rita Lazar for editorial assistance.

1. Abu-Saad H. Assessing children's response to pain. Pain 1984; 19: 163-171.

2. Mather L, Mackie J. The incidence of post-operative pain in children. Pain 1983; 15: 271-282.

3. Acs G, Moore P A, Needleman H L, Shusterman S. The incidence of post-extraction pain and analgesic usage in children. Anesth Prog 1986; 33: 147-151.

4. Acs G, Moore P A, Shusternan S, Needleman H L. The extent of trauma and postextraction pain in children. Pediatr Dent 1988; 10: 210-214.

5. Acs $G$, Drazner $E$. The incidence of post-operative pain and analgesic usage in children. ASDC J Dent Child 1992; 59: 48-52.

6. Brännström M, Nordenvall K J, Hedstrom K G. Periodontal tissue changes after intraligamentary anesthesia. ASDC J Dent Child 1982; 49: 417-423.

7. Quilici D L. Contraindication in the use of the periodontal ligament injection. Compendium 1990; 11: 96-100.

8. Ashkenazi M, Blumer S, Eli I. Effectiveness of intra-sulcular computerized-delivery anesthesia in primary molars. J Am Dent Assoc 2005; 136: 1418-1425.

9. Ran $D$, Peretz B. Assessing the pain reaction of children receiving periodontal ligament anesthesia using a computerized device (Wand). J Clin Pediatr Dent 2003; 27: 247-250.

10. Asprey J R. Postoperative analgesic prescription and administration in a pediatric population. J Pediatr Nurs 1994; 9: 150-157.

11. Malamed S F. Sedation: a guide to patient management. 4th ed. pp 337. St. Louis: CV Mosby Co, 2003.

12. Grover PS, Lorton $L$, Hollinger J. A clinical study of the incidence of pain after operative treatment visit: part II. J Prosthet Dent 1984; 51: 369-371.

13. Silvestri A R Jr, Cohen S H, Wetz J H. Character and frequency of discomfort immediately following restorative procedures. J Am Dent Assoc 1977; 95: 85-89.

14. Eli I, Baht R, Kozlovsky A, Simon H. Effect of gender on acute pain prediction and memory in periodontal surgery. Eur J Oral Sci 2000; 108: 99-103.

15. Seymour R A, Blair G S, Wyatt FA. Post-operative dental pain and analgesic efficacy. Part I. Br J Oral Surg 1983; 21: 290-297.

16. Eli I. The multidisciplinary nature of pain. In Bergenholz G, Horsted-Bindslev $P$, Reit C (eds) Textbook of endodontology. pp 57-65. Oxford: Blackwell Munksgaard, 2003. 